\title{
Sociotechnical Myths in Development
}

Introduction to a Special Issue

Jean-Philippe Venot and Gert Jan Veldwisch

\section{(2) OpenEdition}

\section{Journals}

Electronic version

URL: http://journals.openedition.org/anthropodev/582

DOI: 10.4000/anthropodev.582

ISSN: 2553-1719

Publisher

APAD - Association pour l'anthropologie du changement social et du développement

\section{Printed version}

Date of publication: 1 December 2017

Number of pages: $7-26$

ISBN: 979-10-93476-05-6

ISSN: 2276-2019

\section{Electronic reference}

Jean-Philippe Venot and Gert Jan Veldwisch, « Sociotechnical Myths in Development », Anthropologie \& développement [Online], 46-47 | 2017, Online since 01 June 2018, connection on 01 May 2019. URL : http://journals.openedition.org/anthropodev/582 ; DOI : 10.4000/anthropodev.582

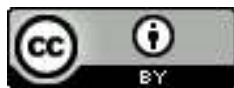

La revue Anthropologie \& développement est mise à disposition selon les termes de la Licence Creative Commons Attribution 4.0 International. 


\title{
Sociotechnical Myths in Development
}

\author{
Introduction to a Special Issue
}

Jean-Philippe Venot, Gert Jan Veldwisch

\section{Introduction ${ }^{1}$}

In the past few years, independently of each other, we encountered ferocious promoters of 'technologies for development', such as drip irrigation, conservation agriculture, the System of Rice Intensification (SRI), or the better known Jatropha or Bt Cotton seeds. The missionary zeal with which these were promoted and defended (and sometimes attacked) struck us. Upon closer scrutiny these were not only technologies for development but rather 'packages of sociotechnical practices' that share many similarities: their loose definitions, the close-knit support networks surrounding them, the aspirations for a better future they embedded and were meant to help achieve, and their mixed relations with science, to name a few ${ }^{2}$.

While mainstream development organizations are nowadays quick to warn against seeing technologies as 'silver bullets' (see, for instance, FAO, 2017, in the field of agriculture; WHO, 2010, regarding the development of a vaccine against malaria; World Bank, 2017, on the issue of Information

${ }^{1}$ We would like to thank all contributors to this Special Issue of Anthropologie \& développement as well as the external reviewers and the members of the editorial committee who contributed to the peer review process. Special thanks to Dominic Glover, Philippe Lavigne Delville, Janwillem Liebrand, and Margreet Zwarteveen who provided insightful comments on an earlier version of the introduction and helped us sharpening our ideas.

${ }^{2}$ The examples we identify here stem from our background: both of us have been working on agricultural water management issues in South and South East Asia, Sub-Saharan Africa, the Mediterranean region and Central Asia for the last ten years. As the special issue illustrates, other similar 'packages' exist in other fields. 
and Communication Technologies in education) ${ }^{3}$, sociotechnical packages such as the one we listed above appear to be still promoted as quasiuniversal solutions. They are bestowed with the potential of resolving multiple interconnected issues finally providing THE answer to development. Building on the diverse contributions that follow, we will highlight how these sociotechnical packages share similarities but also significantly differ from the earlier technologies upon which development has long been prophesized to happen.

In this Special Issue of Anthropologie \& développement we examine the phenomenon of sociotechnical myths in development. Here, a first clarification regarding the terminology we use is needed. By 'myth' we intend a type of intervention that is presented and aspires to provide an universal solution to interconnected complex issues. As they are both neatly bounded in the form of a 'package' yet also loosely defined, dispute or debate over empirical evidence are constitutive elements of myths. We do not aim to dismiss them as 'false' or 'untrue' (an understanding of myth that is both colloquial and normative), but take a more ethnographic approach to unpack how these sociotechnical myths come into being and work with specific reference to the field of development.

Myths are not specific to development, but what makes myths 'in development' different from myths in other fields is that they are grounded in and articulate a moral imperative to act, so as to shape a better future - an aspiration that is difficult to question. Further, the development 'techno-structure' provides a conducive environment for myth making. Indeed, as highlighted by proponents of an actor-oriented analysis of development practices:

"a [development] intervention [is] a 'multiple reality' made of differing cultural perceptions and social interests, and constituted by the ongoing social and political struggles that take place between the social actors involved" (Long and Van der Ploeg, 1989: 226).

\footnotetext{
${ }^{3}$ These statements display striking similarities: though they start (or end) by highlighting that there is no silver bullet to the problem at hand, they centre on highlighting the potential of a specific technology - or a suite of options - to solve that same problem.
} 
In this perspective, development interventions are amenable to debate and disputes that are, as underlined above, constitutive of myths. Maybe more significant as far as myth-making is concerned are the logics and practices of competing development organizations that, however long they have been highlighted by anthropology of development scholars, remain largely disconnected from empirical evidence (Naudet, 1999, for instance frames development as a top-down avenue that is largely about finding problems to [ready-made] solutions).

Despite the rhetoric on the inadequacy of 'silver bullet' approaches, standardized interventions that hold the promises of universal application and large-scale impacts are attractive to global development actors but also a way to legitimize their existence. On the other hand, national administrations have little incentive not to accept these interventions as they come together with significant funding on which they have come to depend. Another specificity of the development sector relates to 'evaluation': as it seldom questions the rationale of interventions (which is grounded in a moral imperative to act; see Long and Van der Ploeg, 1989, and Li, 2007), it actually provides ground for further intervention on the basis of future promises and hence plays a key role in myth making.

The articles in this special issue engage with a range of sociotechnical myths; some of which are world famous (such as vaccines or Randomized Control Trials) and others mostly known among specialists of a given field (such as the System of Rice Intensification, drinking water supply systems). Contributors draw from a wide range of disciplines (Anthropology of Development, Political Ecology, Science and Technology Studies, and Human Geography), and use the notion of myth in different ways to shed light on processes that go beyond our own direct fields of work. Some contributions may also spark thinking on other concepts such as that of model (e.g. Rap, this issue), device (Werner, this issue), or mechanism (Abdelghafour, this issue). This will lead us to clarify the relationships between these concepts in the next section of this introduction. The contributions nevertheless display strong commonalities, confirming our expectation that the processes we observed in the practices around drip irrigation, conservation agriculture and SRI were not coincidental but signal that sociotechnical myths constitute a much wider phenomenon of development practice and policy making. 
In this short introduction, we highlight some of the commonalities and differences across the contributions, which we structure in three sections. First, in the section "What is a sociotechnical myth?", we refine and delineate our conceptual approach and propose a definition of the term 'sociotechnical myth' that builds on an already rich anthropological literature and other, more widely used, concepts. Second, we engage with "Myths as performance" and analyze: "How do sociotechnical myths emerge and what do they do?". Third we stress why studying sociotechnical myths is important, reflecting on the fact that these processes have wide implications for how development works and is understood.

\section{What is a sociotechnical myth?}

As defined in the Oxford Dictionary a myth is:

"a traditional story, especially one concerning the early history of a people or explaining a natural or social phenomenon, and typically involving supernatural beings or events" (Oxford Dictionary, 2017a).

This is the common understanding of myth, often associated with the adjective 'mythological'. A second, related, understanding of myth, still according to the Oxford Dictionary (2017a), is that of "a widely held but false belief or idea". These two definitions tend to posit 'myth' in opposition to 'reality', a duality that has been questioned by anthropologists who draw attention to the close intertwining between the two concepts. In an anthropological reading, myths provide meaning, motivate action and, because they are framed in allegoric ways, they allow maintaining social order while offering the scope to challenge it (see Weiner, 1994, for a discussion of myth and language in anthropology; see also Sen et al., and Rap, this issue, for a discussion on the notion of myth).

In the common imaginary, then, myths are generally associated with terms such as story or tale (Werner, this issue, actually plays on this association in its Tale of "The Prince and the Magic Magnet") in ways that tend to indicate they should be disregarded if one's objective is to understand the 'reality out there'. Building on an already wide literature on the performativity of myth (for instance, Campbell, 1988), this special 
issue starts from a different stance, one that some contributors describe as an anthropological understanding of myth (see Sen et al., this issue). In our understanding, myths are not just inanimate stories; they are very real in the sense that they are actively shaped and reproduced by individuals who may genuinely believe in them or not, for different reasons, and in the context of networks that form supportive coalitions. Just like the discourses of Foucault, myths contribute to shaping the ways people see and act in the world. Myths do this in specific ways, which justifies our use of this precise word. Indeed, as in the common understanding of the term, myths in development resort to beliefs and heroes to change a situation for the better and future promises take precedence over current evidence.

Our understanding of 'myth' builds on other concepts that have been more widely used in the field of development studies, such as that of 'panacea' (Ostrom et al., 2007) or 'narrative' (Roe, 1991). Sen et al. (this issue) and Rap (this issue) also refer to narratives in their study of respectively SRI and irrigation policy making, while Liebrand (this issue) describes maps as graphical representations of narratives. In her work on the governance of human-environment interactions, Elinor Ostrom uses the word "panacea" to highlight the prevalence and limits of applying a single solution to all (environmental) problems (Ostrom et al., 2007) but she does not really engage with the concept at a theoretical level other than highlighting that panaceas go beyond technical fixes. In his work, Roe (1991) highlighted how specific narratives drive and legitimize development practices even though their empirical merits are increasingly questioned. He attributes this persistence to the 'story like' character of narratives that often start from a (real or potential) crisis scenario, provide an explanatory framework for it, and propose a road-map (a cause-andeffect relationship model that reduces uncertainty) to go about it. Roe (1991) considers 'narratives' to be less normative than 'ideology' and more programmatic than 'myth' and equates the latter with words such as 'conventional wisdom', 'puzzle', 'folktale'. He highlights that the word 'myth' is often used in a derogatory way, to dismiss events, and in this view, using the concept may lead to obscuring our understanding of development process - something we tend to disagree with for the reasons stated in this introduction. 
We argue that, as a heuristic tool, the concept of 'myth' allows us to go a step further than these works that shed light on the broad fields of environment and development practice and policy making. The concept of myth indeed conveys a double meaning. First, it is an acknowledgement that 'stories' and 'narratives' (as intended by Roe, 1991) give meaning, drive actions and legitimize them. Several contributions to this special issue for instance show how specific development interventions acquire a mythical character through the elaboration of a convincing narrative. Sen et al. for instance highlight that:

"a myth works through narrative to rationalize disturbances in everyday life and provide incentives for people not to dismiss change" (Sen et al., this issue).

We will come back to the second part of the quote in the next section when we investigate "What do myths do". Second, the concept reminds us of the fact that individuals in the development sector are also human beings with cultures, beliefs, aspirations and rituals including in the production of 'evidence' (Liebrand, this issue, provides an insightful analysis of the production and use of maps as evidence). Here, the concept of myth acts as a reminder that evidence acquires relevance and authority solely through its enactment in closely-nit networks that then provide a space for a specific interpretation of a given situation to flourish (see Mosse, 2004, on this interplay between evidence and interpretation).

The term myth is thus also different from that of 'model', which has notably been used to analyze how specific standardized approaches 'travel' from one place to another (see, among others, Behrends et al., 2014, and Olivier de Sardan et al., 2017). Indeed, the term 'model' embeds an imagery of causality and rationality, which may lead researchers to downplay the issues of agency, practices, ethics and aspirations that are central to the concept of myth and, we argue, to development processes ${ }^{4}$.

${ }^{4}$ Note that the authors we quote, as well as other scholars in the anthropology of development such as David Mosse or Thomas Bierschenk, clearly highlight that the elaboration and spread of 'models' are embedded social practices and sites of struggle. However, there is a risk that these latter aspects are overlooked given the wide use of the word 'model' in the natural sciences (as an analytical explanatory framework to represent 
The concept of 'model' has also been used mostly in relation to 'intervention' and 'policy' with a risk to downplay materiality (an exception being Rottenburg, 2007). This is especially problematic as the belief in technology as a driver of progress and change is a cornerstone of modernity and development practices, meaning that discourses about technologies (the interpretation) are often more performative than the technologies themselves and their application (the evidence). Moreover, what we observe is that development narratives still largely revolve around the capacity of specific sociotechnical packages (that is, complex webs of technical objects, recommended practices, and forms of organizations for their smooth running) to solve grand challenges. Gangneron (this issue) for instance shows this for semi-urban drinking water supply systems and Glover et al. (2017) for drip irrigation and the System of Rice Intensification.

Let us indeed turn towards the second key word of this special issue: the sociotechnical character of the myths that are being discussed in the different contributions.

Technologies have long played a central role in development practices and discourses. Being seen as direct applications of a neutral and objective 'Science', technologies became dominant in public development aid programs in the 1950s when technology transfer programs mushroomed. These were based on the assumption that technical objects had universal applicability, independent of the socioenvironmental contexts in which they were used.

Technologies were thus promoted as 'silver bullets' ${ }^{5}$ to solve grand societal problems such as hunger, poverty, health, or environmental degradation. From the 1970s onwards, these programs faced increased criticism as it became clear that they did not systematically result in

natural processes). See Oliver de Sardan et al. (2017) for further discussions regarding the concepts of model, device and mechanism.

${ }^{5}$ In the story, only a silver bullet can kill the mythical werewolf. According to the Oxford Dictionary a 'silver bullet' means "a simple and seemingly magical solution to a complicated problem" (Oxford Dictionary, 2017b). 
poverty alleviation and could even lead to increased inequalities. In the agricultural sector, for instance, technologies that were promoted as part of the 'Green Revolution' started to be a hotly debated topic - they still are. Critiques notably revolved around the central role given to science and engineering based knowledge (often at the expense of other forms of knowledge; see, among others, Glover et al., 2017) and on the fact that technology transfer programs largely ignored the systemic nature of innovation processes (see, for instance, Geels, 2004, for a generic argument as well as Biggs, 1990, and the collection of essays in Chauveau et al., 1999, and Coudel et al., 2013, for an application to the agricultural sector).

In the 1980s and the 1990s, hence, it seemed the myth of 'development through technology' started to fade, but did it really? Arguably, mainstream development agencies are now quick to stress that there is no 'silver bullet technology' to development challenges or again that there are no 'blueprint approaches'. The change in terminology from 'silver bullet' to 'blueprint' - is not neutral and shows that development organizations have partly internalized the need to go beyond technology alone. But the vocabulary used is still grounded in engineering (after all, a blue print is a reproduction of a design plan or technical drawing characterized by light-coloured lines on a blue background, a process widely used in the field of architecture and industry between the 1860 s and 1940s). The myth of planned intervention that was critically analyzed by Long and Van der Ploeg (1989) still runs deep in the cultures, logics and practices of individuals and organizations as also highlighted in the contributions of Liebrand (this issue) and Rap (this issue) (see also Scott, 1998; Lavigne Delville, 2012). Mosse (2004) reminds us this is strategic rather than sheer blindness; plans and designs serve to align interests, forge alliances, and mobilize funds and support. They are pivotal for the elaboration of sociotechnical networks in which sociotechnical packages thrive.

The era in which 'modern technologies' are widely seen as the starting point of development is far from over. Several contributions to this special issue are clear reminders of how technological artefacts and a vision of Science as objective provider of knowledge still fascinate diverse actors and remain central to development practice. The first is for instance 
exemplified by the contributions of Werner (on Magnetic Resonance Imagery - MRI) and Thiongane et al. (on vaccines); the latter by the contribution of Abdelghafour on the Randomized Control Trials (RCT) approach to evaluation. In many instances however, the technology does not come alone and is promoted as part of a broader sociotechnical package including one or several artefacts (a device) but also a modusoperandi (a mechanism clarifying how the device shall be used and by whom), and an organizational set up in which the device is to be embedded for its 'efficient use' ${ }^{6}$. These sociotechnical packages, we argue, are even more powerful than the technologies of yesterday; this is because they are represented, appreciated, talked about, and implemented differently by different actors - yet they keep a certain coherence. Similarly to boundary objects (Star and Griesemer, 1989), they are both neatly bounded to lend themselves to universality claims, yet offer a scope for interpretation and adjustment: technologies were (relatively) static; sociotechnical packages are dynamic.

If specific technologies could be dismissed relatively easily on the grounds that they were ill-adapted to the context of implementation (the gap between the assumed potential of a specific artefact and its lack of adoption is partly what triggered critiques of Rogers, 1983, innovation diffusion model), it is more difficult to do so with sociotechnical packages. The latter make explicit reference to the importance of 'context' and one of the reasons for their appeal is that they display enough malleability ${ }^{7}$ to be adjusted to it. Clear examples of these are the System of Rice Intensification (Sen et al., this issue, and Serpantié, this issue), drip

\footnotetext{
${ }^{6}$ Philippe Lavigne Delville noted that the packages we were talking about were "technicoinstitutional" or "technico-organizational" rather than sociotechnical as they largely overlooked the complexity of social dynamics and often limited themselves to standard recommendations regarding the organizational or institutional set up in which a specific device ought to be used. We prefer using the term 'sociotechnical package' - it is a way to highlight that the packages we discuss are embedded and enacted through sociotechnical networks.

${ }^{7}$ De Laet and Mol (2000) for instance attribute the 'success' of the Zimbabwean Bush pump to its malleability (they use the concept of fluidity that goes beyond the technical ability to fit in the context of implementation).
} 
irrigation (Venot, 2016) and Conservation Agriculture (Giller et al., 2009) ${ }^{8}$. Further some sociotechnical myths have less to do with technological artefacts than with 'the way they land in new contexts': see for instance the cases of social enterprises for drip irrigation (Venot, 2016) and PublicPrivate-Partnerships for the MenAfricVac ${ }^{\circledR}$ (Thiongane et al., this issue). Finally, the (scientific and practitioners) debates regarding the 'boundaries' of any sociotechnical package (what is it made of), its domain of applicability, and its impacts are now an integral part of the package rather than something 'outside of it' as clearly shown in the case of Randomized Control Trials (Abdelghafour, this issue), MenAfriVac ${ }^{\circledR}$ (Thiongane et al., this issue) and SRI (Serpantié, this issue).

In the following section, we further describe the processes that underpin sociotechnical myth formation and what they do (i.e. their performance). We highlight that they share many similarities with earlier technical fixes - largely because they are embedded and contribute to a modernist and linear understanding of development.

Myths as performance: How do myths emerge, what do they do?

We now explore what sociotechnical myths in development do, how they are being constituted, held together, and made to work. We argue that sociotechnical myths in development: 1) create meaning and motivate action, and 2) allow for creating and preserving credibility and legitimacy within epistemic networks.

\section{Creation of meaning and "rendering technical"}

A common aspect of myths in development is their appeal to a higher morale, aspiration and/or hope. Myths embody an ideal image of what the world should tend to, in that they help in imagining and imaging something that is not (yet) there, emphasizing 'potential' and projecting a desirable

\footnotetext{
${ }^{8}$ Today, development actors have partly internalized that sociotechnical packages need to account for, and be adjusted to, the context though there is still a tendency to dismiss the latter - and the people in it - rather than the (potential of the) intervention when results (in terms of adoption for instance) do not match expectations.
} 
future. This is something several contributions engage with: Werner (this issue) for instance provides an insight on the role of images (literally speaking) in the case of MRI while Liebrand (this issue) analyze the performativity of maps.

Connections and associations are made to something that is 'Good' in the abstract sense, or to values assumed to be universal (though they reflect a narrow vision of progress, mostly Western and male dominated), such as equity, progress, development, and modernity. As highlighted by several authors ${ }^{9}$, these promises have a performative role and are crucial resources to create sociotechnical networks in which specific packages will thrive - partly because they allow displacing the attention away from current dynamics that may be disputed.

Associations are not only made with 'values' and 'promises' but also to the global frameworks that are meant to embody them so as to enrol global development actors in supporting sociotechnical networks. Unsurprisingly, several of the myths this special issue engages with have been closely linked to the former Millennium Development Goals and the current Sustainable Development Goals. The System of Rice Intensification (SRI) is intentionally related to sustainable intensification and food security (Sen et al., this issue; Serpantié, this issue) as is drip irrigation (Venot, 2016); the MenAfriVac ${ }^{\circledast}$ (Thiongane et al., this issue) and MRI (Werner, this issue) are tools to improve health care, and advance good health and wellbeing. A drinking water supply system (Gangneron, this issue) is meant to address the need for clean water (and sanitation). Finally, the myths of Irrigation Management Transfer (Rap, this issue) and Randomized Control Trials (Abdelghafour, this issue) are of another nature; they relate to the neoliberal goal of efficient institutions and use of (scarce) resources and assets.

Connections can be made between specific sociotechnical packages and greater objectives in the form of maps (see for instance Liebrand, this issue, in the case of irrigation development in Nepal), images (see the

${ }^{9}$ See for instance Burkhardt (2001) on agricultural biotechnology and Geels and Smit (2000) on Information and Communication Technologies (ICT). 
illustrations in the contribution of Serpantié, this issue), but this mostly happens through narratives, that is, stories that have a beginning, a middle and an end, and provide an explanatory and programmatic framework (Roe, 1991) on how the sociotechnical package will contribute to achieve the 'greater good'. Programmatic frameworks generally follow a common structure (problem definition, identification of a potential solution, implementation, and evaluation) and display some level of novelty contrasting the sociotechnical myth with past approaches. The 'novelty' of the MRI ('high-tech'), RCT (a 'sound and objective' evaluation framework), or the MenAfriVac ${ }^{\circledR}$ ('affordable') is clear in the contributions of Werner (this issue), Abdelghafour (this issue) and Thiongane et al. (this issue). Gangneron (this issue) also shows how drinking water supply systems in semi-urban areas are presented as offering a significant shift from other techniques such as dug-wells and human powered pumps. Another case in point is how the promoters of SRI carefully avoided the word 'technology' to pass on the idea that the package was somehow an alternative to past approaches to intensification (Sen et al., this issue). But novelty is not enough for a sociotechnical package to become a sociotechnical myth, which, as said above, vehicles aspirations, values, and ideals (see, for instance, the insightful analysis of Liebrand, this issue, on planned irrigation development as a vehicle for 'masculinity').

This is where we turn towards a key process in development, that, to paraphrase Li (2007), of "black-boxing" and "rendering technical" (that is equating development processes to simple cause-and-effect relationships - see also Long and Van der Ploeg, 1989, for a critique). Several contributors to this special issue indeed highlight that what is at play in the making of myth is a game of lights and shadows whereby some issues are put to the fore while others are largely overlooked, with a subsequent risk of marginalization of some actors and points of view. This clearly comes out in the analysis of the MenAfriVac ${ }^{\circledR}$ by Thiongane et al. (this issue) whereby a vaccine - developed against a specific strain of Meningitis - is imbued with the prospect of eradicating meningitis epidemics even though these are linked to a diversity of serotypes. Similarly, the contribution of Gangneron (this issue) shows that, beyond the promises of universal coverage, drinking water supply systems in semi-urban areas tend to exclude the poorest who cannot afford higher water rates. Two processes appear to be central to "rendering technical". First, the identification of an 
'initial success' that gives ground to a search for replication (see, for instance Rap, this issue). Second, standardization - a search for commonalities and abstraction that is partly driven by a "will to improve" (Li, 2007) through the production of 'guidelines' and activities of 'packaging' (Glover et al., 2017) that make it possible for the sociotechnical package to travel - a precondition for myth making.

\section{Motivating action within supportive coalitions}

The processes described in the preceding section take place and shape farreaching sociotechnical networks but these often share a commonality: they are centred around one or several 'heroes' who feature prominently in the narrative that underpins the myth and who bring change because of their remarkable character (Liebrand, this issue, reminds us that these are often men, making an argument that links Western ideas of progress to masculinity).

Personification is indeed another element of sociotechnical myths that different contributors highlight (Thiongane et al., this issue, for instance draw our attention to Marc LaForce; Serpantié, this issue, to Fr. Henri de Laulanié and Norman Uphoff; Liebrand, this issue, to the 'Irrigation Man' and the 'Water Emperor' in Nepal). In Actor Network Theory these heroes are often referred to as "The Prince" (Werner, this issue), the "spokesperson", or the "(Schumpeterian) entrepreneur" (Akrich et al., 1988a). They play a key role in "creating interessement" (Akrich et al., 1988b) and in establishing a tightly-knit yet multifaceted network of actors (a supportive coalition) through which the myth acquires a wider reach (see for instance Abdelghafour, thid issue, and Thiongane, this issue, describing the coalitions around Randomized Control Trials and the MenAfriVac ${ }^{\circledR}$, respectively). Rap (this issue) also shows that these entrepreneurs are not 'fixed' in time, e.g. some individuals (in his case specific Mexican irrigation policy makers) may emerge as especially powerful spoke-persons in the very process of myth making, because they act and represent specific constituencies in the sociotechnical network.

In such networks, the myth inspires, convinces, mobilizes and holds together, leading its subscribers to be characterized as 'followers' or 'believers' by outsiders who draw parallels to religious movements, something Giller et al. (2009) clearly point out when titling their paper on 
conservation agriculture "an heretic's view" in a rather provocative way. Several of the contributors to this special issue (Liebrand, Rap, Sen et al., Thiongane) also make this link to religion when highlighting the 'rituals' that are involved in myth making.

Beliefs, a will to improve and aspirations towards a greater good are, however, not the only engine of myth making, far from it. Actors in the network strategically engage with the myth - hence giving it its aura because it aligns with their interest and agenda and in turn legitimizes their action. The strength of the network comes from two main characteristics: 1) a high level of ingenuity and adaptability to redefine the sociotechnical package (or rather decide to shed light on some aspects and leave others in the shadows) to create interessement among a wide diversity of actors, and 2) an ability to re-order and unite itself behind its common morale when faced with external critique. The network indeed provides a space in which myths are stabilized through the strategic elaboration of particular interpretation of events and the shaping of success (see for instance Rap, this issue, Thiongane, this issue, and Mosse, 2005 , for a generic argument).

\section{Creation and preservation of credibility: $A$ dialectic relationship to Science}

While myths in the first place mobilize and maintain their support networks with reference to a higher 'Good', they also strategically engage with the construction of knowledge and its authority. This requires balancing between on the one hand a simple cause-to-effect story, something easy to catch and market, and on the other a more systematic underpinning of the narrative.

There is a dialectic relation between myth and science; science is used as a way to build legitimacy (enrolment of universities and individual scientists, publications), but it can also be dismissed as being 'expert' knowledge, disconnected from field realities and action.

The contributions to this special issue illustrate this duality. The RCT myth (Abdelghafour, this issue) is grounded in a normative view of science (more specifically in the superiority of 'unbiased statistics') and of the relationship between science and policy, a vision that is particularly 
appealing to development agencies and private foundations. As an 'evaluation myth', it is particularly powerful to legitimize certain ideologies (in that case the need for an economically efficient use of financial resources) and heavily critiqued among social science researchers. In a contrasting way, the SRI myth structured itself around the idea of 'field observations' and against the tenets of the 'mainstream' rice science that underpinned the Green Revolution of the 1960s and 1970s, so much so that Serpantie (this issue) calls for 'sound agronomic research' to better assess the dynamics and impacts of SRI.

Often central to the scientific debates around sociotechnical myth is the selection of indicators to assess the validity and legitimacy of an intervention. What we observe, in many cases, are cautiously orchestrated (self) evaluations (see Abdelghafour, this issue, on RCT; Serpantié, this issue, on SRI; and Venot, 2016, on drip irrigation). In-house analyses of results allow for selection of beneficial statistics (number of drip kits sold, number of farmers adopting specific package, number of people vaccinated, number of water connections, etc.) that can be presented to the 'outside world' while other aspects can be internally reframed as points for improvement. There, again, future promises take precedence over current observations.

Further, as sociotechnical myths often have an open/loose definition of both packages and contexts, they are well positioned to defend themselves by discrediting critical studies on the basis of partial implementation of the package and/or a wrong application context. The malleability of the myth can be both called upon to claim universality and as a disclaimer when results turn out not to be as expected.

What we argue here is that more or different research is unlikely to change myth-making dynamics. On the contrary, (scientific) controversy is an integral part of myth making as also highlighted by Sen et al. (this issue). Sociotechnical myths are indeed characterized by conflicting (over)statements that lend themselves to heated discussions and polarized debate. Referring to Gregory Batson, Stone (2015) in his study of biotechnology called this "schismogenesis", a self-amplifying process of divergence. Such process is not incidental; the scientific - and sometimes heated - debates around conservation agriculture (Giller et al., 2009), drip irrigation (Kuper et al., 2017), or meningitis vaccines (Thiongane et al., this 
issue), to name a few, contribute to "raising the profile" of these sociotechnical packages. It may well be that the sociotechnical networks that sustain sociotechnical myths are shaped in such a way that they create the conditions for such debate, a way to facilitate organized dissent and attract attention. After all, if researchers engage with these myths whether positively or negatively - this is, in itself, a sign of their relevance. This raises the issue of how critical social researchers can engage with these myths in a constructive way.

\section{Why and how to engage with sociotechnical myths?}

The concept of sociotechnical myth, we argue, sheds new light on development practices and policies as well as on why some of these interventions acquire a status of 'model that calls for replication'. This happens through a stabilized yet malleable interpretation of the nature and promises of such interventions; an interpretation that is strategically and carefully crafted within a specific-yet-wide-reaching supportive coalition. The concept also calls for 'unpacking' what often remains 'black boxed' and thus bringing into the light underlying motivations and ideologies with their related risks of marginalization.

As critical social scientists, however, our relationship to sociotechnical myths is dualistic. At first, there is a clear inclination to be critical, which clearly emerges from many of the contributions in this special issue. This critical attitude is often justified on the grounds that sociotechnical myths simplify a complex reality, legitimize reforms in line with highly inequitable dominant ideologies, and hence result in marginalization. As relevant as these critiques may be (we actually share many of these views), they do little in terms of changing the state of affairs. On the contrary, they may even reinforce the myths they aim at discrediting (see also Liebrand, this issue, for a similar argument). (Heated) scientific debate being a key element of myth making, a positivist science response is indeed ineffective in containing sociotechnical myths.

This does not mean we would shy away from engaging with the messy reality of development 'out there' and notably in activities of coalition building for what we consider to be meaningful and just. Some would say this is not the role of researchers who have to keep a certain distance from 
events - so as to understand them. But remaining in an ivory tower is also a political choice - a strong one that equally contributes to shaping development realities but in terms largely set by others. As myths have the capacity to unleash an incredible level of energy and creativity among a wide diversity of actors, they can actually be brought to bear on development realities; as Sen et al. (this issue) tell us, because of their malleability, they "can [also] guide people and their communities in dealing with change without determining clear-cut solutions in advance". What is needed is a constructive engagement with these myths and the dominant normative frameworks that underpin them and, for the most engaged of us, the framing of alternative myths along different lines.

\section{Bibliography}

AKRICH M., CALLON M., LATOUR B., 1988a, “À quoi tient le succès des innovations? 2 : le choix des porte-parole", Gérer et comprendre, Annales des Mines, $12: 14-29$.

AKRICH M., CALLON M., LATOUR B., 1988b, “À quoi tient le succès des innovations? 1 : L'art de l'intéressement", Gérer et comprendre, Annales des Mines, 11: 4-17.

BEHRENDS A., PARK S.J., ROTTENBURG R., 2014, "Travelling Models: Introducing an Analytical Concept to Globalisation Studies", in BEHRENDS A., PARK S.J., ROTTENBURG R. (eds.), Travelling Models in African Conflict Management. Translating Technologies of Social Ordering, Leyden, Brill: 1-40.

BURKHARDT J., 2001, "Agricultural biotechnology and the future benefits argument", Journal of Agricultural and Environmental Ethics, 14: 135145 .

BIGGS S.D., 1990., "A multiple Source of innovation model of agricultural research and technology promotion", World Development, 38(1): 1481-1499.

CAMPBELL J., 1988, The power of myth, New York, Doubleday.

CHAUVEAU J.P., CORMIER SALEM M.C., MOLLARD E. (eds.), 1999, L'innovation en agriculture : questions de méthodes et terrains d'observation, Paris : IRD, $362 \mathrm{p}$. 
COUdel E., DEVAUtour H., FAURE G., SOULARD C. and HUBERT B., 2013, "Renewing innovation systems in agriculture and food. How to go towards more sustainability?", Wageningen, The Netherlands, Wageningen Academic Publishers.

DE LAET M. and MOL A., 2000, "The Zimbabwe Bush Pump: Mechanics of a fluid technology", Social Studies of Science, 30(2): 225-263.

FOOD AND AGRICULTURAL ORGANIZATION OF THE UNITED NATIONS (FAO), 2017, "Reduce rural poverty", http://www.fao.org/about/what-we-do/so3/en/, Last visited 31/08/2017.

GEELS F.W., 2004, "From sectoral systems of innovation to socio-technical systems: Insights about dynamics and change from sociology and institutional theory", Research policy, 33: 897-920.

GEELS F.W., SMIT W.A., 2000, "Failed technologies futures: pitfalls and lessons from a historical perspective", Futures, 32: 867-885.

GILLER K.E., WITTER E., CORBEelS M. and TITTONELL P., 2009, "Conservation agriculture and smallholder farming in Africa: The heretics" view", Field Crops Research, 114(2009): 23-34.

GLOVER D, VENOT J.P. and MAAT H., 2017, "On the movement of agricultural technologies: packaging unpacking and situated reconfiguration", in SUMBERG T. (ed.), Agronomy for Development: The politics of knowledge in agricultural research, London and New York, Routledge: 14-30.

LAVIGNE DELVILLE P., 2012, “Affronter I'incertitude? Les projets de développement à contre-courant de la 'révolution du management de projet'", Revue Tiers Monde, 211 : 153-168.

KUPER M., VENOT J.P. and ZWARTEVEEN M., 2017, "Introduction: Panda or Hydra? The untold stories of drip irrigation", in VENOT J.P., KUPER M. and ZWARTEVEEN M. (eds.), Drip irrigation for Agriculture: untold stories of efficiency, innovation and development, Routledge, Abingdon \& New York: 1-15.

LI T.M., 2007, The will to improve. Governmentality, development, and the practice of politics, Durham, Duke University Press.

LONG N. and VAN DER PLOEG J D., 1989, "Demythologizing planned intervention: An actor perspective", Sociologia Ruralis, 29(3/4): 226-249.

MOSSE D., 2004, "Is good policy unimplementable? Reflections on the ethnography of aid policy and practice", Development and Change, 35(4): 639-671. 
MOSSE D., 2005, Cultivating development. An ethnography of aid policy and practice, London, Pluto Press.

NAUDET J.D., 1999, Trouver des problèmes aux solutions: 20 ans d'aide au Sahel. Paris, OCDE.

OLIVIER DE SARDAN J.P., DIARRA A. and MOHA M., 2017, "Traveling models and the challenges of pragmatic contexts and practical norms; the case of maternal health", Health Research Policy and Systems, 15(Suppl. 1): 7187.

OSTROM E, JANSSEN M.A. and ANDERIES J.M., 2007, "Going beyond panaceas", Proceedings of the National Academy of Sciences, 104(39): 15176-15178.

OXFORD DICTIONARY, 2017a, "Myth", https://en.oxforddictionaries.com/definition /myth, Last visited 31/08/2017.

OXFORD DICTIONARY, 2017b, "Silver bullet", https://en.oxforddictionaries.com /definition/silver_bullet, Last visited 31/08/2017.

ROE E.M., 1991, "Development narratives, or making the best of blueprint development", World Development, 19(4): 287-300.

ROTTENBURG R., 2007, Far-fetched facts. A parable of development aid, Cambridge, MIT Press.

ROGERS E.M., 1983, Diffusion of Innovations, $3^{\text {rd }}$ edition, New York, MacMillan.

SCOTT J.C., 1998, Seeing like a state - How certain schemes to improve Human condition have failed, New Haven and London, Yale University Press.

STAR S.L. and GRIESEMER J.R., 1989, "Institutional ecology. 'Translations' and boundary objects: Amateurs and professionals in Berkeley's museum of vertebrate zoology", Social Studies of Sciences, 19(3): 387-420.

STONE G.D., 2015, "Biotechnology, Schismogenesis, and the demise of Uncertainty", Journal of Low and Policy, 47(1): 29-49.

VENOT J.P., 2016. "A success of some sort: drip irrigation, social enterprises and drip irrigation in the developing world", World Development, 79(3): 6981.

WEINER J.F., 1994, "Myth and metaphor", in INGOLD T. (ed.), Companion Encyclopedia of Anthropology, London and New York, Routledge: 591612. 
WORLD HEALTH ORGANIZATION (WHO), 2010, "A research agenda for malaria eradication", by Dr Margaret Chan Director-General of the WHO, http: //www.who.int/dg/speeches/2010/malaria_20100326/en/, Last visited $31 / 08 / 2017$.

WORLD BANK, 2017, "Education provides the analogue foundation for our digital lives", by Michael Trucano, http://blogs.worldbank.org/edutech/ education-provides-analogue-foundation-our-digital-lives, Last visited 31/08/2017.

\section{Niviviv}

Jean-Philippe Venot is Researcher in Geography and Development Studies

IRD, UMR G-EAU, University of Montpellier (France)

and Water resources Management Group, Wageningen University (The Netherlands)

E-mail : jean-philippe.venot@ird.fr

Gert Jan Veldwisch is Assistant Professor in Water \& Development

Water Resources Management Group, Wageningen University (The Netherlands)

E-mail : gertjan.veldwisch@wur.nl 